\title{
Análise de roteiros teatrais aplicados no ensino de criptógamas em um Curso de Ciências Biológicas no Município de Fortaleza-CE
}

Analysis of theatrical scripts applied in the teaching of cryptogames in a Course of Biological

Sciences in the City of Fortaleza-CE

Análisis de los guiones teatrales aplicados en la enseñanza de criptógamas en un Curso de Ciencias

Biológicas en la Ciudad de Fortaleza-CE

Recebido: 24/02/2021 | Revisado: 04/03/2021 | Aceito: 10/03/2021 | Publicado: 18/03/2021

Paula Amanda Santiago do Nascimento

ORCID: https://orcid.org/0000-0003-3023-0387

Universidade Estadual do Ceará, Brasil

E-mail: paula.asantiagon@gmail.com

Marcos Adelino Almeida Filho

ORCID: https://orcid.org/0000-0002-3803-5116

Universidade Federal Rural do Semi-Árido, Brasil E-mail: paula.asantiagon@gmail.com

Lucas Farias Pinheiro

ORCID: https://orcid.org/0000-0002-4722-7558 Universidade Estadual do Ceará, Brasil E-mail: luccas.fpinheiro@gmail.com

Josiany Costa de Souza

ORCID: https://orcid.org/0000-0001-7787-8928 Instituto Federal de Educação, Ciência e Tecnologia do Ceará, Brasil

E-mail: cjosiany@gmail.com

Oriel Herrera Bonilla

ORCID: https://orcid.org/0000-0002-9140-6086 Universidade Estadual do Ceará, Brasil E-mail: oriel.herrera@uece.br

Eliseu Marlônio Pereira de Lucena ORCID: https://orcid.org/0000-0002-8190-1702 Universidade Estadual do Ceará, Brasil E-mail: eliseu.lucena@uece.br

Jeanne Barros Leal de Pontes Medeiros ORCID: https://orcid.org/0000-0002-7047-7838 Universidade Estadual do Ceará, Brasil E-mail: jeanne.pontes@uece.br Lydia Dayanne Maia Pantoja ORCID: https://orcid.org/0000-0002-4446-7230 Universidade Estadual do Ceará, Brasil E-mail: lydia.pantoja@uece.br

Roselita Maria de Souza Mendes ORCID: https://orcid.org/0000-0003-0705-2914 Universidade Estadual do Ceará, Brasil E-mail: roselita.mendes@uece.br Bruno Edson-Chaves

ORCID: https://orcid.org/0000-0001-6031-5336 Universidade Estadual do Ceará, Brasil E-mail: bruno.edson@uece.br

\begin{abstract}
Resumo
No Ensino Superior há certa carência da aplicação de metodologias didáticas que estimulem e despertem novos sentidos nos discentes. Dentro desse contexto, a confecção de roteiros teatrais permite que os alunos apliquem na prática conhecimentos trabalhados em sala de aula de modo lúdico e inovador. Esta pesquisa objetivou avaliar a adequação de roteiros escritos e encenados por alunos da disciplina de Morfologia e Taxonomia de Criptógamas do curso de Ciências Biológicas da Universidade Estadual do Ceará para o Ensino Superior e/ou a outros níveis escolares. Participaram da pesquisa, 40 alunos representantes de dois semestres diferentes, os quais tiveram que elaborar roteiros teatrais relacionados aos conteúdos botânicos vistos na disciplina em foco, em seguida, tais roteiros foram analisados através dos métodos de SMOG (tradicional e adaptado) e Flesch. Na avaliação SMOG tradicional, todos os roteiros estavam aptos ao público universitário, exceto "E da água brotou" que também se aplicava a alunos do Ensino Médio; na versão
\end{abstract}


adaptada do SMOG, somente os roteiros "Briófitas do sertão" e "Charles Jones: em busca da Pteridófita perdida" estavam adequadas ao público universitário, e as demais ao nível médio, e "E da água brotou" para o Ensino Fundamental II. Na escala Flesch, predominou o nível de legibilidade razoavelmente fácil. Os roteiros mostraram-se adequados ao público e de fácil leitura, o que demostra a relevância do uso dessa técnica para o ensino-aprendizado em qualquer faixa etária, assim sendo uma atividade enriquecedora resultante de atividades desenvolvidas junto à Prática como Componente Curricular, componente obrigatório nos cursos de licenciatura.

Palavras-chave: Botânica; Licenciatura; Arte educação.

\begin{abstract}
In Higher Education there is a certain lack of application of didactic methodologies that stimulate and awaken new senses in students. Within this context, the making of theatrical scripts allows students to apply in practice knowledge worked in class in a playful and innovative way. This research aimed to evaluate the suitability of scripts written and staged by students of Morphology and Taxonomy of Cryptogams of the course of Biological Sciences of the State University of Ceará for higher education and/or other school levels. 40 students representing two different semesters participated in the research, which had to elaborate theater scripts related to the botanical contents seen in the subject in focus, then such scripts were analyzed through the methods of SMOG (traditional and adapted) and Flesch. In the traditional SMOG assessment, all scripts were suitable for the university public, except "E da água brotou" which also applied to high school students; in the adapted version of SMOG, only the scripts "Briófitas do sertão" and "Charles Jones: em busca da pteridófita perdida" were suitable for the university public, and the others at the high school level, and "E da água brotou" for junior high school. On the Flesch scale, the reasonably easy level of readability predominated. The scripts proved to be appropriate for the public and easy to read, which evidences the relevance of the use of this technique for teaching and learning in any age group, thus being an enriching activity resulting from activities developed with the Practice as a Curriculum Component, a mandatory component in licenciate courses.
\end{abstract}

Keywords: Botany; Licenciate course; Art education.

\title{
Resumen
}

En la educación superior hay una cierta falta de aplicación de metodologías didácticas que estimulen y despierten nuevos sentidos en los estudiantes. En este contexto, la elaboración de guiones teatrales permite a los estudiantes aplicar en la práctica los conocimientos trabajados en clase de manera lúdica e innovadora. Esta investigación tenía por objeto evaluar la idoneidad de los guiones escritos y escenificados por los estudiantes de Morfología y Taxonomía de los Criptógamos del curso de Ciencias Biológicas de la Universidad Estatal de Ceará para la enseñanza superior y/o otros niveles escolares. 40 estudiantes que representaban a dos semestres diferentes participaron en la investigación, que tuvo que elaborar guiones teatrales relacionados con los contenidos botánicos vistos en el tema en cuestión, luego dichos guiones fueron analizados a través de los métodos de SMOG (tradicional y adaptado) y Flesch. En la evaluación tradicional del SMOG, todos los guiones eran aptos para el público universitario, excepto "E da água sprotou" que también se aplicaba a los estudiantes de secundaria; en la versión adaptada del SMOG, sólo los guiones "Briófitas do sertão" y "Charles Jones: em busca da Pteridófita perdida" eran aptos para el público universitario, y los demás a nivel de secundaria, y "E da água sprotou" para la escuela primaria II. En la escala de Carne, predominaba el nivel razonablemente fácil de lectura.Los guiones resultaron ser apropiados para el público y fáciles de leer, lo que pone de manifiesto la pertinencia del uso de esta técnica para la enseñanza y el aprendizaje en cualquier grupo de edad, siendo así una actividad enriquecedora resultante de las actividades desarrolladas con la Práctica como Componente del Plan de Estudios, un componente obligatorio en los cursos de licenciatura.

Palabras clave: Botánica, Licenciado, Educación artística.

\section{Introdução}

O Ensino Superior é o nível no qual se verifica menor diversidade em relação às práticas didáticas. A educação universitária é, muitas vezes, desenvolvida através de metodologias tradicionais, onde as aulas expositivas predominam em detrimento de outras metodologias ativas; sendo esta, a experiência e formação dada aos profissionais que a reproduzirão na educação do nível fundamental e médio (Gil, 2013), o que configura um problema grave, considerando que os alunos de cursos de licenciatura serão os docentes cuja atuação na Educação Básica exigirá habilidades e competências mais complexas (Brasil, 2017). O pensamento reducionista e conservador, adotado ainda por muitas instituições, é considerado nos estudos de Saheb (2015), como um dos impasses ainda não superados pelas universidades e que continuam sendo reproduzidos pelos próprios professores. 
Nessa perspectiva, o ser humano procura por inovações na intenção de acompanhar a evolução da humanidade, e no âmbito da sala de aula, esta mesma realidade é vivenciada pelos professores, uma vez que a diversidade de alunos é cada vez maior e naturalmente há a necessidade de novas metodologias de ensino, que resgatem o interesse dos estudantes para o aprendizado, como é o caso da implementação de ferramentas lúdicas (Silva, 2017; Covos et al., 2018). Ou seja, é necessário que o docente tenha um olhar reflexivo para (re)pensar as práticas pedagógicas e suas abordagens didáticas utilizadas (Sano, 2021).

Entre as diferentes possibilidades metodológicas de ensinagem, destacam-se as estratégias lúdico-artísticas, entre as quais as peças teatrais podem ser utilizadas. O teatro auxilia a relacionar a teoria com a prática, ao mesmo tempo em que se mostra um importante instrumento de divulgação científica e recurso para a formação docente (Moreira \& Marandino, 2015; Silva, 2018; Valério, Silva \& Oliveira, 2019). De modo que proporciona a alunos, professores e comunidade uma socialização do conhecimento de modo lúdico, podendo ser extremamente importante no contexto educacional (Bezerra \& Nakayama, 2019).

A produção de roteiros permite que os alunos atuem de forma ativa na construção do trabalho, inspirando novas formas de criação, estimulando habilidades de leitura, escrita e construção de sentidos, o que acaba tendo a finalidade de orientar todos os envolvidos no processo de produção (Paz, 2019; Silva, 2020). Quando associado ao ensino de botânica, área que perpassa pelas dimensões ambiental, ética, médica, estética, filosófica, cultura e histórica (Ursi et al., 2018), tal estratégia pode auxiliar a mitigar os efeitos da cegueira botânica.

A cegueira botânica foi um termo cunhado por Wandersee e Schussler em 2001 que refere-se incapacidade de enxergar ou notar as plantas presentes no ambiente, o que gera a: (i) incapacidade de reconhecer a importância das plantas para a biosfera e socidade humana, (ii) incapacidade de admirar as plantas por seus aspectos estéticos e biológicos, e (iii) percepção de que as plantas são inferiores aos animais, e, portanto, deveriam apresentar menor atenção/valorização humana (Ursi, Freitas \& Vasques, 2021).

A partir disso, este trabalho objetivou avaliar a adequação de roteiros de peças teatrais escritos e encenados por alunos da disciplina de Morfologia e Taxonomia de Criptógamas do curso de Licenciatura em Ciências Biológicas da Universidade Estadual do Ceará (Campus do Itaperi), Fortaleza-CE, para o Ensino Superior e/ou a outros níveis escolares.

\section{Metodologia}

Esta pesquisa se configura como exploratória, possui natureza qualitativa, o que pode levar a um aprimoramento de ideias e envolver levantamento bibliográfico (Prodanov \& Freitas, 2013).

O estudo se baseou na análise de roteiros produzidos pelos alunos do curso presencial de Licenciatura em Ciências Biológicas do Centro de Ciências da Saúde da Universidade Estadual do Ceará - UECE (Campus do Itaperi), Fortaleza-CE, que cursaram a disciplina Morfologia e Taxonomia de Criptógamas, referente ao $3^{\circ}$ semestre do curso, em dois semestres distintos.

No percurso metodológico os alunos foram divididos em 4 a 5 grupos de apresentações (dependendo do semestre), as equipes foram formadas de acordo com a afinidade dos membros participantes, e em seguida houve o sorteio dos temas, previamente, delimitados pelo professor regente, assim os alunos divididos em grupos encenaram os roteiros produzidos por eles mesmos.

No primeiro semestre que foi executada a atividade, a quantidade de alunos foi suficiente para formação de cinco grupos; no segundo semestre, devido a menor quantidade de alunos, apenas quatro grupos foram formados, sendo que os dois temas de Briófitas foram fundidos em um só. O nome dos esquetes e os acrônimos usados para identificá-los constam no Quadro 1. 
Quadro 1. Tema e título dos nove esquetes produzidos nos dois semestres (Sem.) em que a atividade foi executada.

\begin{tabular}{|ccll|}
\hline Sem. & Acrônimo & Tema & Título do esquete \\
\hline $1^{\circ}$ & A & Fungos & Alice no país dos fungos \\
$1^{\circ}$ & B & Algas & Ariel e os feiticeiros de Hogwarts \\
$1^{\circ}$ & C & Briófitas - Hepatophyta e Antocerophyta & Musgo, pra que te quero? \\
$1^{\circ}$ & D & Briófitas - Briophyta & A feiticeira Verde, o mago negro e as briófitas \\
& & & dançantes \\
$1^{\circ}$ & E & Pteridófitas & E da água brotou \\
$2^{\circ}$ & F & Fungos & Casos de Fungos \\
$2^{\circ}$ & G & Algas & Na Maré Vermelha \\
$2^{\circ}$ & H & Briófitas - Hepatophyta, Antocerophyta, Briophyta & Briófitas do sertão \\
$2^{\circ}$ & I & Pteridófitas & Charles Jones: em busca da Pteridófita perdida \\
\hline
\end{tabular}

Fonte: Autores (2021).

Quanto aos roteiros, estes foram estruturados livremente pelos estudantes, os quais poderiam criar peças inéditas ou adaptar os enredos a partir de obras já existentes. Todos os roteiros foram entregues com antecedência para avaliação prévia às apresentações, realizada pelo professor e pelos monitores da disciplina.

Os roteiros definitivos entregues no dia das apresentações foram aqueles que seguiram corretamente a estrutura da construção textual do estilo de peça teatral, conforme recomendação de Granero (2011). Por isso, dos nove esquetes que se apresentaram (Quadro 1), apenas oito deles tiveram seus roteiros analisados quanto a leiturabilidade e legibilidade, tendo um dos roteiros (esquete "A feiticeira Verde, o mago negro e as briófitas dançantes") apenas discorrido uma narração fora do padrão textual exigido.

Para a avaliação e validação dos roteiros a serem apresentados, utilizou-se o método da leiturabilidade, de fácil aplicação e possível de ser utilizado em documentos curtos, para o levantamento e análise de dados para os cálculos necessários quanto ao grau de leiturabilidade é o SMOG (McLaughlin, 1969).

Os roteiros foram divididos em três partes com, aproximadamente, a mesma quantidade de linha entre estes blocos. De todos os roteiros foram selecionadas 30 frases, sendo estas dez do início, dez do meio e dez do final dos textos. Em seguida, foram contabilizadas quantas palavras trissílabas ou polissílabas estavam presentes em cada oração. Por fim, somamos os resultados, tiramos a raiz quadrada, mais próxima, e adicionamos três ao valor obtido do cálculo anterior (Holland, 2012), tal valor indica o número de anos escolares são necessários para boa leiturabilidade do texto. No texto essa análise será referida como SMOG tradicional. O valor apresentado no SMOG varia muito com cada texto, não tendo um valor mínimo nem máximo ideal; mas este valor deve ser confrontado com dados de trabalhos que fazem a relação sobre os anos de estudo e nível escolar, como o de Santos (2010) presente no Quadro 2, e assim avaliar se o texto analisado no SMOG tem um nível de leiturabilidade adequado ao nível de ensino a qual o texto se propõe 
Quadro 2. Quantidade de anos de escolaridade por equivalência escolar.

\begin{tabular}{|ll|}
\hline Anos de Estudo & Série Escolar \\
\hline Sem instrução ou $<1$ ano & Nunca frequentou a escola ou não concluiu $1^{\circ}$ ano do Ensino Fundamental. \\
$1-3$ anos & Conclusão do $2^{\circ}, 3^{\circ}$ ano ou cursando o $4^{\text {a }}$ ano do Ensino Fundamental. \\
$4-7$ anos & Conclusão do $5^{\circ}$ ano ou cursando o $6^{\circ}, 7^{\circ}$ ou $8^{\circ}$ ano do Ensino Fundamental. \\
$8-10$ anos & Conclusão do $9^{\circ}$ ano do Ensino Fundamental ou cursando ou $1^{\circ}$ ou $2^{\circ}$ ano do Ensino Médio. \\
$11-14$ anos & Conclusão do $3^{\mathrm{a}}$ ano do Ensino Médio ou $1^{\mathrm{o}}, 2^{\circ}$ e $3^{\circ}$ períodos do Ensino Superior. \\
$15 \geq \operatorname{anos}$ & Conclusão do $4^{\circ}, 5^{\circ}$ e $6^{\circ}$ período do Ensino Superior ou mestrado e doutorado. \\
\hline
\end{tabular}

Fonte: Adaptado de Santos (2010).

Uma vez que o SMOG tem como base a língua inglesa, alguns autores como Nunes e Oliveira-Júnior (2000) e Miranda et al. (2009) defendem uma adaptação desta técnica para a língua portuguesa. Isso se deve pelo fato da língua portuguesa ter mais palavras polissílabas e paroxítonas que o inglês (Valente \& Martins, 2004) e isso poderia ter desvios nos resultados. Devido a isto, além do uso do SMOG tradicional, foi utilizado um SMOG adaptado para o português considerado a contagem apenas das palavras polissílabas. Esta também foi uma recomendação de Amaral (2021).

Baseado no comprimento das palavras e das frases do texto é possível medir a legibilidade utilizando-se dois índices: o Índice de Legilibilidade de Flesch-Kinkaid e o Índice de Facilidade de Leitura de Flesch (Bulla et al., 2003).

Os roteiros dos esquetes foram operacionados pelo software Microsoft Word 2010 para a identificação dos elementos necessários para o cálculo do índice de Facilidade de leitura de Flesch, para avaliar suas dificuldades de leitura. Esse índice classifica o texto em escala de 100 pontos e o resultado está demonstrado no Quadro 3 (Lobato, Caçador \& Gazzinelli, 2013).

Quadro 3. Escore Flesch distribuído de acordo com nível de dificuldade.

\begin{tabular}{|c|c|}
\hline Escala Flesch & Nível de Legibilidade \\
\hline $0-29$ & Muito difícil \\
$30-49$ & Difícil \\
$50-59$ & Razoavelmente difícil \\
$60-69$ & Padrão \\
$70-79$ & Razoavelmente fácil \\
$80-89$ & Fácil \\
$90-100$ & Muito fácil \\
\hline
\end{tabular}

Fonte: Lobato, Caçador e Gazzinelli (2013).

\section{Resultados e Discussão}

A análise dos oitos roteiros pelo SMOG tradicional permitiu identificar que o esquete "E da água brotou" foi o que apresentou menor nível de leiturabilidade sendo aplicado a alunos do $9^{\circ}$ ano do Ensino Fundamental e $1^{\circ}$ e $2^{\circ}$ ano do Ensino Médio; os demais esquetes apresentaram índice de SMOG entre 11 e 14, estando aptos para serem compreendidos por alunos do $3^{\circ}$ ano do Ensino Médio e $1^{\circ}$ a $3^{\circ}$ período do Ensino Superior (Quadro 4). 
Quadro 4. Resumo dos resultados da avaliação SMOG quanto à leiturabilidade dos roteiros considerando palavras a partir de trissílabas e classificação do público adequado aos roteiros. EM. Ensino Médio; ES. Ensino Superior.

\begin{tabular}{|c|c|c|}
\hline Acrônimo das Esquetes & SMOG & Nível escolar do público adequado aos roteiros \\
\hline $\mathrm{A}$ & 11 & Conclusão do $3^{\mathrm{a}}$ ano do EM ou $1^{\circ} ; 2^{\circ}$ e $3^{\circ}$ períodos do ES \\
\hline $\mathrm{B}$ & 11 & Conclusão do $3^{\mathrm{a}}$ ano do EM ou $1^{\circ} ; 2^{\circ}$ e $3^{\circ}$ períodos do ES \\
\hline $\mathrm{C}$ & 11 & Conclusão do $3^{\mathrm{a}}$ ano do EM ou $1^{\circ} ; 2^{\circ}$ e $3^{\circ}$ períodos do ES \\
\hline $\mathrm{E}$ & 10 & Conclusão do $9^{\circ}$ ano do EF ou cursando ou $1^{\circ}$ ou $2^{\circ}$ ano do EM \\
\hline $\mathrm{F}$ & 13 & Conclusão do $3^{\mathrm{a}}$ ano do EM ou $1^{\circ} ; 2^{\circ}$ e $3^{\circ}$ períodos do ES \\
\hline G & 13 & Conclusão do $3^{\mathrm{a}}$ ano do EM ou $1^{\circ} ; 2^{\circ}$ e $3^{\circ}$ períodos do ES \\
\hline $\mathrm{H}$ & 14 & Conclusão do $3^{\mathrm{a}}$ ano do EM ou $1^{\mathrm{o}} ; 2^{\circ}$ e $3^{\circ}$ períodos do ES \\
\hline I & 13 & Conclusão do $3^{\mathrm{a}}$ ano do EM ou $1^{\circ} ; 2^{\circ}$ e $3^{\circ}$ períodos do ES \\
\hline
\end{tabular}

Fonte: Autores (2021).

Na análise do SMOG adaptado (Quadro 5) o roteiro do esquete "E da água brotou” estava adaptado ao Ensino Fundamental II; os roteiros “Alice no país dos fungos", “Ariel e os feiticeiros de Hogwarts", "Musgo, pra que te quero?” e "Na Maré Vermelha" adaptados ao $9^{\circ}$ ano do Ensino Fundamental e $1^{\circ}$ e $2^{\circ}$ ano do EM; os demais adaptados ao $3^{\circ}$ ano do EM e $1^{\circ}$ ao $3^{\circ}$ período do Ensino Superior.

Os esquetes em questão, apesar de desenvolvidos no Ensino Superior e para esse público, demonstram, mediante análise SMOG, que há certa democratização de saberes entre os diferentes níveis de facilidade/dificuldade e períodos escolares, com muitos esquetes podendo ser utilizados para público de Ensino Médio e/ou Ensino Fundamental, garantindo maior apropriação e possibilidades de entendimento dos conteúdos e reforçando que a linguagem teatral pode ser empregada nos diferentes níveis escolares para facilitar a compreensão dos assuntos ministrados.

Quadro 5. Resumo dos resultados da avaliação SMOG quanto à leiturabilidade dos roteiros considerando apenas palavras polissílabas e classificação do público dos roteiros. EF. Ensino Fundamental; EM. Ensino Médio; ES. Ensino Superior.

\begin{tabular}{|c|c|c|}
\hline Acrônimo das Esquetes & SMOG & Nível escolar do público adequado aos roteiros \\
\hline A & 9 & Conclusão do $9^{\circ}$ ano do EF ou cursando ou $1^{\circ}$ ou $2^{\circ}$ ano do EM \\
\hline B & 8 & Conclusão do $9^{\circ}$ ano do EF ou cursando ou $1^{\circ}$ ou $2^{\circ}$ ano do EM \\
\hline $\mathrm{C}$ & 8 & Conclusão do $9^{\circ}$ ano do EF ou cursando ou $1^{\circ}$ ou $2^{\circ}$ ano do EM \\
\hline $\mathrm{E}$ & 6 & Conclusão do $5^{\circ}$ ano do EF ou cursando $6^{\circ}, 7^{\circ}$ ou $8^{\circ}$ ano do EF \\
\hline $\mathrm{F}$ & 10 & Conclusão do $3^{\mathrm{a}}$ ano do EM ou $1^{\circ}, 2^{\circ}$ e $3^{\circ}$ períodos do ES \\
\hline $\mathrm{G}$ & 9 & Conclusão do $9^{\circ}$ ano do EF ou cursando ou $1^{\circ}$ ou $2^{\circ}$ ano do EM \\
\hline $\mathrm{H}$ & 11 & Conclusão do $3^{\mathrm{a}}$ ano do EM ou $1^{\circ}, 2^{\circ}$ e $3^{\circ}$ períodos do ES \\
\hline I & 11 & Conclusão do $3^{\mathrm{a}}$ ano do EM ou $1^{\circ}, 2^{\circ}$ e $3^{\circ}$ períodos do ES \\
\hline
\end{tabular}

Fonte: Autores (2021).

Os dados encontrados neste estudo são importantes, pois demonstram que os roteiros das peças desenvolvidas pelos discentes, em sua maioria, estão adequados para o nível básico. Logo, a produção e publicação dos enredos pode ser um estímulo, visto que as peças teatrais na Educação Básica ainda são pouco utilizadas pelos docentes (Santos \& Guilardi Junior, 2016). Neste âmbito, podem tornar-se um mecanismo favorável ao conhecimento científico lúdico, sociocientífico e interativo de assuntos estudados em sala de aula (Pereira 2018; Santos et al., 2020). 
A predominância dos esquetes "Casos de Fungos", "Briófitas do sertão" e "Charles Jones: em busca da Pteridófita perdida" (especialmente as duas últimas) como roteiros para o nível superior é endossada pela avaliação de legibilidade pelo índice de facilidade de leitura da escala Flesch (Quadro 6). Tais roteiros diferem dos demais considerados razoavelmente fáceis de serem lidos. Esta análise também demonstra que a análise do SMOG adaptado reflete um nível de leiturabilidade semelhante à análise de Flesch.

Quadro 6. Avaliação do nível de facilidade da leitura dos roteiros pelo método de Flesch.

\begin{tabular}{|ccc|}
\hline Acrônimo das Esquetes & Escala Flesch & Nível de Legibilidade \\
\hline A & 78 & Razoavelmente fácil \\
B & 75 & Razoavelmente fácil \\
C & 76 & Razoavelmente fácil \\
E & 77 & Razoavelmente fácil \\
F & 66 & Médio/Padrão \\
G & 78 & Razoavelmente fácil \\
H & 56 & Razoavelmente difícil \\
I & 47 & Difícil \\
\hline
\end{tabular}

Fonte: Autores (2021).

De modo geral, se analisarmos os Quadro 4, 5 e 6 veremos que os roteiros do segundo semestre de realização dessa prática didática foram de mais alto nível de complexidade: linguagem, leiturabilidade e tecnicidade, coniventes ao público-alvo, alunos universitários.

Um roteiro apresenta um somatório de elementos capazes de demonstrar um sentido desejado, na qual inclui um enredo, diálogos, informações visuais e sonoras, apresentando assim uma função comunicativa importante e adaptativa de conteúdo (Toledo, 2018). A averiguação observada nos Quadro 4, 5 e 6, corrobora com a ideia de Bergamo (2010) de que com as adequações corretas, o lúdico se aplica a qualquer idade. Tem que haver equilíbrio entre a linguagem utilizada e o conteúdo abordado de acordo com a necessidade do público.

Mesmo que, predominantemente, os roteiros em questão demonstrem uma leitura fácil, o teor dos roteiros, segundo a avaliação SMOG padrão, teriam que ser adaptados, sob um planejamento pedagógico didático diferenciado, para aplicação na Educação Básica.

\section{Considerações Finais}

Os alunos em sua grande maioria conseguiram elaborar enredos envolventes, adequados ao Ensino Superior sem perder a facilidade da leitura. Vale ressaltar ainda, a importância das análises realizadas no presente estudo para aproximar técnicas de ensino e aprendizagem com a realidade e o contexto dos alunos e assim verificar a adequação das atividades efetuadas para a sua respectiva faixa etária. As avaliações demostraram que muitos dos roteiros elaborados também são acessíveis aos alunos da Educação Básica, podendo servir como uma importante estratégia para socializar os conhecimentos botânicos e auxiliar a diminuir a cegueira botânica.

A avaliação do SMOG adaptada mostra ser mais pertinente que o SMOG tradicional, pois este se aproxima mais dos resultados do nível de facilidade da leitura através do método de Flesch. Utilizando estes dois parâmetros, o roteiro E ("E da água brotou") foi o que mostrou maior facilidade de compreensão e o roteiro I (“Charles Jones: em busca da Pteridófita perdida”) o de mais difícil compreensão. Coincidentemente ambos se referem ao mesmo assunto (Pteridófitas), demonstrando que 
independente do tema é possível elaborar roteiros com diferentes níveis de facilidade/dificuldade de leitura, dependendo da criatividade dos alunos no momento da elaboração do roteiro.

A elaboração de roteiros teatrais pode vir a fomentar nos futuros professores o desejo de apostar nessa proposta de ensino e aprendizagem dos conteúdos. Os dados ainda revelam que o teatro pode transcender os currículos escolares, bem como as faixas etárias, podendo ser executável por alunos dos mais diversos níveis escolares, inclusive no Ensino Superior, e assim gerar profissionais mais criativos, críticos, empáticos, cooperativos, proativos, desprovidos de inibição, comunicativos, adaptativos e capazes de achar soluções para problemas do cotidiano.

Quando associados ao ensino de botânica/criptógamas o uso da elaboração de roteiros teatrais pode tornar o ensino desta área mais próximo a realidade do aluno, seja na educação básica ou superior, tornando a aplicação de conceitos mais acessível, estimulando o aprendizado e ajudando a diminuir a cegueira botânica.

\section{Referências}

Amaral, M. V., Dantas, A. R. C., Rodrigues, M. M. A, Fernandes, T. A. A., Lucena, E. M. P., Edson-Chaves, B., \& Bonilla, O. H. (2021). Leiturabilidade de cartilhas ambientais editadas pelo IBAMA - CE. In: Edson-Chaves, B., Mendes, R. M. S., Bonilla, O. H., Lucena, E. M. P. Contextualizando o ensino de Botânica e Ecologia. Atena, p. 17-26.

Bergamo, M. (2010). O uso de metodologias diferenciadas em sala de aula: uma experiência no ensino superior. Revista Eletrônica Interdisciplinar, 2(4), 1-10. Bezerra, M. F. C. \& Nakayama, L. (2019). Contribuições da Revista Educação Ambiental em Ação pra difusão do teatro, como instrumentos de ensino e aprendizagem. Revista Educação Ambiental em Ação, (68).

Brasil. (2017). Ministério da Educação e Cultura. Base Nacional Comum Curricular. Brasília: MEC.

Bulla, M. C., Benincasa, C. C., Goldim, J. C. \& Franciscone C. F. M. (2003). O uso de termos de consentimento informado nas áreas assistenciais do Hospital de Clínicas de Porto Alegre. Revista da AMRIGS, 47(2), 101-103.

Covos, J. S., Covos, J. F., Rodrigues, F. R. \& Ouchi, J. D. (2018). O novo perfil de alunos no Ensino Superior, e a utilização de jogos lúdicos para facilitação do ensino aprendizagem. Revista Saúde em Foco, 2018, 62-74.

Gil, A. C. (2013). Didática do ensino superior (8th ed.). Atlas.

Granero, V. V. (2011). Como usar o teatro na sala de aula. Contexto.

Holland, A. (2012). SMOG - ultimate list of online content readability tests. Recuperado de http://blog.raventools.com/ultimate-list-of-online-contentreadability-tests/

Lobato, L., Caçador, B. \& Gazzinelli, M. (2013). Legibilidade dos termos de consentimento livre e esclarecido em ensaios clínicos. Revista Bioética, 21(3), 557565 .

McLaughlin, G. (1969). SMOG grading: a new readability formula. Journal of Reading, 12, 639-646.

Miranda, V. C., Fêde, A. B. S., Lera, A. T., Ueda, A., Antonangelo, D. V., Brunetti, K., Riechelmann, R. \& Giglio, A. D. (2009). Como consentir sem entender? Revista da Associação Médica Brasileira, 55(3), 328-334.

Moreira, L. M. \& Marandino, M. (2015). Teatro de temática científica: conceituação, conflitos, papel pedagógico e contexto brasileiro. Ciência \& Educação, 21(2), 511-523.

Nunes, M. G. V. \& Oliveira Junior, O. N. (2000). O processo de desenvolvimento do revisor gramatical ReGra. Anais do Seminário Integrado de Software e Hardware, Curitiba, PR, Brasil, 1.

Paz, M. D. G. (2019). A cartilha Três vivas para o bebê! em audiolivro: a criação de um roteiro para peça radiofônica. 162 f. Dissertação (Mestrado em Literatura e Cultura) - Universidade Federal da Bahia, Salvador.

Pereira, A. de S. (2018). O processo de elaboração de peças de teatro científico na formação inicial de professores de química. Tecné, Episteme e Didaxis: TED, (44), 185-200.

Prodanov, C. C. \& Freitas, E. C. (2013). Metodologia do trabalho científico: métodos e técnicas da pesquisa e do trabalho acadêmico (2nd ed.). Rio Grande do Sul: Editora da Universidade Freevale.

Saheb, D. (2015). Os sete saberes de Morin e sua contribuição para a Formação de educadores ambientais. Anais da Reunião Nacional da ANPED, Florianópolis, SC, Brasil, 37.

Sano, P. T. (2021) Prefácio. In: Vasques, D. T., Freitas, K. C. \& Ursi, S. Aprendizado ativo no ensino de Botânica. Instituto de Biociências, Universidade de São Paulo, p. 4-6.

Santos, A. M. (2010). Leiturabilidade: É possível medi-la em livros infanto-juvenis? PUC. 
Research, Society and Development, v. 10, n. 3, e34310313279, 2021 (CC BY 4.0) | ISSN 2525-3409 | DOI: http://dx.doi.org/10.33448/rsd-v10i3.13279

Santos, E. A. R. \& Guilardi Junior, F. (2016). Jogos teatrais no ensino da tabela periódica para estudantes da Educação de Jovens e Adultos (EJA). Anais do Encontro Nacional de Ensino de Química, Florianópolis, SC, Brasil, 18.

Santos, M. J. dos, Grillo, M. G., Catão, V. \& Mello, R. M. A. V. de. (2020). Teatro científico na Educação Bá sica: catalisando diálogos interdisciplinares entre ciência e arte. Trilhas Pedagógicas, 10(12), 294-307.

Silva, L. C. (2018). A fantástica fábrica da química: contribuições de uma peça de teatro científico para educação em química. 108 f. Dissertação (Mestrado em Educação em Ciências) - Universidade Federal de Itajubá, Itajubá.

Silva, M. C. (2020). Contos, roteiros e curtas-metragens: uma proposta de ensino para a EJA. 239 f. Dissertação (Mestrado em Letras) - Universidade Federal de Uberlândia, Uberlândia.

Silva, R. M. da. (2017). O lúdico como ferramenta facilitadora no processo de ensino aprendizagem nas turmas de $1^{\circ}$ ao $3^{\circ}$ ano na Escola Presidente Emílio Garrastazu Médici - Itaíba - Pernambuco - Brasil. 121 f. Dissertação (Mestrado em Ciências da Educação) - Universidad Autónoma de Asunción, Asunción.

Toledo, R. B. M. de. (2018). Adaptação em vídeo das regulamentações institucionais dos cursos de graduação da Universidade Federal do Triângulo Mineiro . 96 f. Dissertação (Mestrado em Inovação Tecnológica) - Universidade Federal do Triângulo Mineiro, Uberaba.

Ursi, S., Barbosa, P. P., Sano, P. T. \& Berchez, F. A. S. (2018). Ensino de Botânica: conhecimento e encantamento na educação científica. Estudos Avançados, 32(94), 7-24.

Ursi, S, Freitas, K. C. \& Vasques, D. T. (2021). Cegueira Botânica e sua mitigação: um objetivo central para o processo de en sino-aprendizagem de Biologia. In: Vasques, D. T., Freitas, K. C. \& Ursi, S. Aprendizado ativo no ensino de Botânica. Instituto de Biociências, Universidade de São Paulo, p. $12-30$.

Valente, F. \& Martins, M. A. (2004). Competências metalinguísticas e aprendizagem da leitura em duas turmas do $1 .^{\circ}$ ano de escolaridade com métodos de ensino diferentes. Análise Psicológica, 22(1), 193-212.

Valério, J. S., Silva, L. C. \& Oliveira, J. R. S. (2019). Contribuições do teatro de divulgação científica por meio da peça O Mágico de O2. Ensino de Ciências e Tecnologia em Revista, 9(2), 67-81. 